\title{
The Salts of Fatty Acids as Precursors for Preparation of Silver Nanoparticles in Organic Solvents
}

\author{
V.N. GLUSHKO*, E.E. ANISIMOVA and L.I. BLOKHINA \\ Federal State Unitary Enterprise «State Scientific Research Institute of Chemical Reagents and High \\ Purity Chemical Substances» (FSUE «IREA»), 3, Bogorodskiy val, Moscow, 107076, Russia. \\ ${ }^{*}$ Corresponding author E-mail: tetrazoli@yandex.ru \\ http://dx.doi.org/10.13005/ojc/320404
}

(Received: July 11, 2016; Accepted: August 11, 2016)

\begin{abstract}
The silver salts of fatty acids were studied as precursors for the preparation of colloidal dispersions of silver nanoparticles and UHMWPE (ultra-high-molecular-weight polyethylene) composite with silver nanoparticles, as well as the composition, the spectra and SEM (scanning electron microscopy) results.
\end{abstract}

Keywords: Silver laurate, silver palmitate, ascorbic acid, differential scanning spectroscopy, microscopy, plasmon resonance, ethylene glycol, ethanol, methanol, reduction, polymer matrix.

\section{INTRODUCTION}

Interest in the silver nanoparticles and materials with their use is increasing rapidly mainly due to their unusual physical characteristics different from the properties of the corresponding compact materials ${ }^{1-4}$.

Colloidal solutions of the silver nanoparticles have an antimicrobial effect with a wide pharmacological spectrum, they can be used for creation of the nanosorbents for producing bactericidal paints and enamels, nanomaterials for creation of antiviral and fungicidal fabric and nonwoven disposable and non-disposable textile materials applied in hospitals, packaging materials that can significantly increase the shelf life of food products $^{5-6}$.

\section{Theoretical analysis}

Nowadays, the creation of metal nanoparticles is one of the fastest growing areas of modern nanotechnology, which allows obtaining materials with unique properties.

It is proposed a lot of physical, chemical, biochemical methods for the preparation of colloidal nanosized particles, including cryochemical reduction, vacuum evaporation, and use of pulsed lasers ${ }^{7}$. 
Metal nanoparticles are lyophobic colloids with low aggregate stability. Their exceptionally high chemical reactivity is based on the evolved interphase, the excess energy of their surface atoms. Calculations have shown that with a decrease in the size of the spherical particles in the three orders of magnitude (from $1 \mu \mathrm{m}$ to $1 \mathrm{~nm}$ ), their specific surface area is also increased by three orders of magnitude (from 0.5 to $500 \mathrm{~m}^{2} / \mathrm{g}$ ), and the proportion of surface atoms reaches tens of percent. All this leads to spontaneous processes of nanoparticles aggregation and actualizes the problem of their stabilization ${ }^{8}$.

Among the main methods of stabilization are:

- functionalization of NP (nanoparticle) surface by groups or protective layers - adsorption of the surfactant with the functional groups of different nature occurs on the NP surface, thiols, carboxylic acids, polyacrylic acid, polydimethylsiloxane, various surfactants, etc. are the most commonly used for these purposes (stabilization in Langmuir-Blodgett films and synthesis of «core-shell» NPs);

- NP localization on the surface of the carriers of different nature - on beads of different nature, with the characteristic size of about hundreds of nanometers.

One of stabilization methods is a matrix isolation, which is used in the form of various types of polymers (organic and inorganic polymers, ceramic - and others) $)^{1,9,10}$.

The literature describes a method for producing monodisperse particles of silver in the thermal decomposition of its carboxylates with a general formula $\mathrm{C}_{n} \mathrm{H}_{2 n} \mathrm{O}_{2} \mathrm{Ag}(\mathrm{n}=6,8,10,12,14,16,18,20,22)$, which are major components of photo thermally developable materials ${ }^{11}$.

The ultimate goal of our research is to study the possibility of admission of silver nanoparticles into the polymer using silver salts of fatty acids as a precursor (silver carboxylates), and therefore, at first we carried out the work to determine the conditions for obtaining the silver nanoparticles by reduction of above mentioned compounds in an organic medium.

\section{MATERIALS AND METHODS}

A series of experiments was carried out in order to investigate the possibility of obtaining colloid solutions of silver nanoparticles by reduction of silver salts of fatty acids, namely silver laurate and silver palmitate, using an organic reducing agent in an organic solvent media in order to determine their properties and stability. These salts are practically insoluble compounds, with the exception of their limited solubility in ethanol and methanol, in which they are dissolved at a concentration of $10^{-3}-10^{-4} \mathrm{M}$ that allows to carry out experiments on their basis in order to obtain the silver nanoparticles.

We obtained silver palmitate and laurate using the general procedure: an aqueous solution of silver nitrate is added to an aqueous acid solution and the precipitate of silver palmitate or laurate salts are filtered off respectively. Preparation of these compounds was confirmed by microanalysis and analysis of the silver content.

Reagents with the following characteristics were used in the experiments:

Lauric acid - mp. $44^{\circ} \mathrm{C} ; 98.9 \%$

Palmitic acid - mp. $62.9^{\circ} \mathrm{C} ; 98.1 \%$

Silver nitrate $-99.9 \%$

Caustic soda - $99.8 \%$

Ethylene glycol $-99.7 \%$

Ethanol - 96.0\%

Methanol - 99.9\%

Ascorbic acid - 99.9\%

\section{Preparation of silver palmitate- $\mathrm{C}_{16} \mathrm{H}_{31} \mathrm{O}_{2} \mathrm{Ag}$ and} laurate- $\mathrm{C}_{12} \mathrm{H}_{23} \mathrm{O}_{2} \mathrm{Ag}$

$0.0375 \mathrm{M}$ of $\mathrm{NaOH}$ was added to a suspension of $0.02 \mathrm{M}$ of palmitic or lauric acid in 100 $\mathrm{cm}^{3}$ of water at $60^{\circ} \mathrm{C}$, heated to $80^{\circ} \mathrm{C}$, the resultant solution was cooled to $10^{\circ} \mathrm{C}$, filtered off and dried. Yield of sodium salts of carboxylates is $91 \%$.

A solution of $0.02 \mathrm{M}$ of sodium salt of palmitic (lauric) acid in $350 \mathrm{~cm}^{3}$ of $7-\%$ ethyl alcohol was heated to $80^{\circ} \mathrm{C}$ and $0.02 \mathrm{M} \mathrm{AgNO}_{3}$ solution in 100 $\mathrm{cm}^{3}$ of water was added. After stirring for 1 hour, the precipitate of silver carboxylate was filtered off. 
Identified \%

Silver laurate

C - 46.93; 46.88

Calculated \%

$\mathrm{H}-7.83 ; 7.87$

C - 46.92

$\mathrm{H}-7.55$

Silver palmitate

C - 52.87; $52.46 \quad$ C -52.85

$\mathrm{H}-8.55 ; 8.68 \quad \mathrm{H}-8.53$

Further studies were carried out to obtain colloidal solutions of silver nanoparticles from such salts.

\section{Method 1}

$20 \mathrm{~cm}^{3}$ of ethanol was added to $0.0061 \mathrm{~g}$ of silver laurate $\left(C=10^{-3} \mathrm{M}\right)$ and stirred for 3 hours at $50^{\circ} \mathrm{C} .10 \mathrm{~cm}^{3}$ of ascorbic acid solution with a concentration of 10-3 $\mathrm{M}$ was poured in ethylene glycol. The solution turned yellow. The peak of low intensity with a maximum $415 \mathrm{~nm}$ was detected at the plasmon resonance spectrum. Dispersion was stable throughout the day (Fig. 1).

\section{Method 2}

$20 \mathrm{~cm}^{3}$ of methanol was added to $0.0061 \mathrm{~g}$ of silver laurate $\left(C=10^{-3} \mathrm{M}\right)$ and ascorbic acid solution in ethylene glycol with a concentration of $10^{-3} \mathrm{M}$. It was stirred for two hours at a temperature of $50^{\circ} \mathrm{C}$ and $10 \mathrm{~cm}^{3}$ of ascorbic acid solution was poured in ethylene glycol with a concentration of

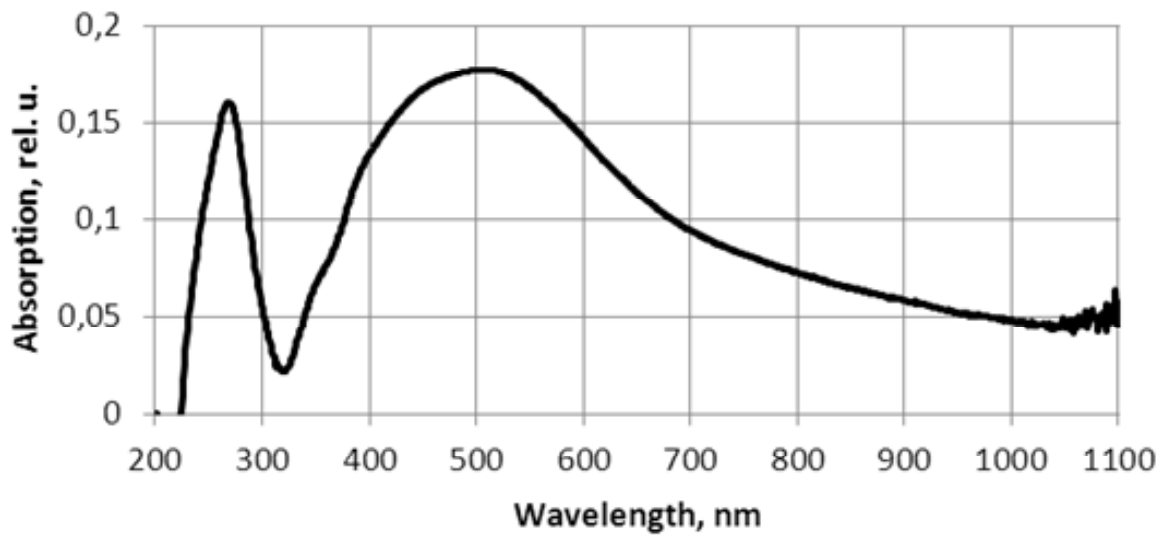

Fig. 1: Plasmon resonance spectrum of colloidal solution of silver nanoparticles prepared from silver laurate

Table 1: Preparation of silver nanoparticles from silver carboxylates

\begin{tabular}{|c|c|c|c|c|c|}
\hline $\begin{array}{l}\text { Silver salt } \\
\text { Concentra-tion, } \\
\mathrm{mol} / \mathrm{l}\end{array}$ & $\begin{array}{c}\text { Solvent } \\
\text { Volume, } \\
\text { ml }\end{array}$ & $\begin{array}{c}\text { Reducing agent } \\
\text { Concentra-tion, } \\
\text { mol/l }\end{array}$ & $\begin{array}{c}\text { Solvent } \\
\text { Volume, } \\
\text { ml }\end{array}$ & $\begin{array}{c}\lambda \max \\
\mathrm{nm}\end{array}$ & Stability \\
\hline Silver laurate $10^{-3}$ & $\begin{array}{l}\text { Ethanol } \\
20 \mathrm{ml}\end{array}$ & Ascorbic acid10-3 & $\begin{array}{c}\text { Ethylene glycol } \\
10 \mathrm{ml}\end{array}$ & 505 & $\begin{array}{l}\text { Stable for } \\
24 \text { hours }\end{array}$ \\
\hline Silver laurate $10^{-3}$ & $\begin{array}{l}\text { Methanol } \\
20 \mathrm{ml}\end{array}$ & Ascorbic acid $10^{-3}$ & $\begin{array}{l}\text { Ethylene glycol } \\
10\end{array}$ & - & Aggregates \\
\hline Silver laurate $10^{-4}$ & $\begin{array}{c}\text { Ethanol } \\
10 \mathrm{ml}\end{array}$ & Ascorbic acid $10^{-4}$ & $\begin{array}{c}\text { Ethanol } \\
10\end{array}$ & - & $\begin{array}{l}\text { Nanoparticles } \\
\text { are not formed }\end{array}$ \\
\hline Silver laurate $10^{-4}$ & $\begin{array}{c}\text { Ethanol } \\
20 \mathrm{ml}\end{array}$ & Ascorbic acid $10^{-4}$ & $\begin{array}{l}\text { Ethylene glycol } \\
20\end{array}$ & 410 & $\begin{array}{l}\text { Aggregates in } \\
15 \text { minutes }\end{array}$ \\
\hline Silver palmitate $10^{-4}$ & $\begin{array}{l}\text { Ethanol } \\
20 \mathrm{ml}\end{array}$ & Ascorbic acid $10^{-3}$ & $\begin{array}{l}\text { Ethylene glycol } \\
10\end{array}$ & 445 & $\begin{array}{l}\text { Stable for } \\
24 \text { hours }\end{array}$ \\
\hline Silver palmitate $10^{-3}$ & $\begin{array}{c}\text { Methanol } \\
10\end{array}$ & Potassium citrate $10^{-3}$ & $\begin{array}{l}\text { Ethylene glycol } \\
50\end{array}$ & - & Aggregates \\
\hline
\end{tabular}


$10^{-3} \mathrm{M}$. The solution was pale yellow and turned transparent after 10 minutes, therefore the plasmon resonance spectrum failed to be taken.

\section{Method 3}

$10 \mathrm{~cm}^{3}$ of ascorbic acid solution in ethanol at a concentration of $10^{-4} \mathrm{M}$ was poured at room temperature to $10 \mathrm{~cm}^{3}$ of silver laurate solution in ethanol at a concentration of $10^{-4} \mathrm{M}$ and stirred in magnetic stirrer. Silver aggregated.

\section{Method 4}

$20 \mathrm{~cm}^{3}$ of ascorbic acid in ethylene glycol with a concentration of $10^{-4} \mathrm{M}$ was poured at room temperature to a solution of silver laurate in $20 \mathrm{~cm}^{3}$ of ethanol with a concentration of $10^{-4} \mathrm{M}$ and stirred. The reaction mass turned yellow, which indicated the formation of nanoparticles, but after 15 minutes the silver aggregated.

\section{Method 5}

$10 \mathrm{~cm}^{3}$ of ascorbic acid solution in ethylene glycol $\left(\mathrm{C}=10^{-3} \mathrm{M}\right)$ was poured to $10^{-4} \mathrm{M}$ solution of silver palmitate in $20 \mathrm{~cm}^{3}$ of ethanol while stirring in magnetic stirrer. The solution became yellow. The plasmon resonance spectrum contains an absorption band with a maximum at $420 \mathrm{~nm}$ (Fig. 2). The dispersion was stable for one day.

\section{Method 6}

$50 \mathrm{~cm}^{3}$ of potassium citrate solution in ethylene glycol with a concentration of $10^{-3} \mathrm{M}$ was poured to $10 \mathrm{~cm}^{3}$ solution of silver palmitate in methanol $\left(C=10^{-3} \mathrm{M}\right)$ while stirring in magnetic

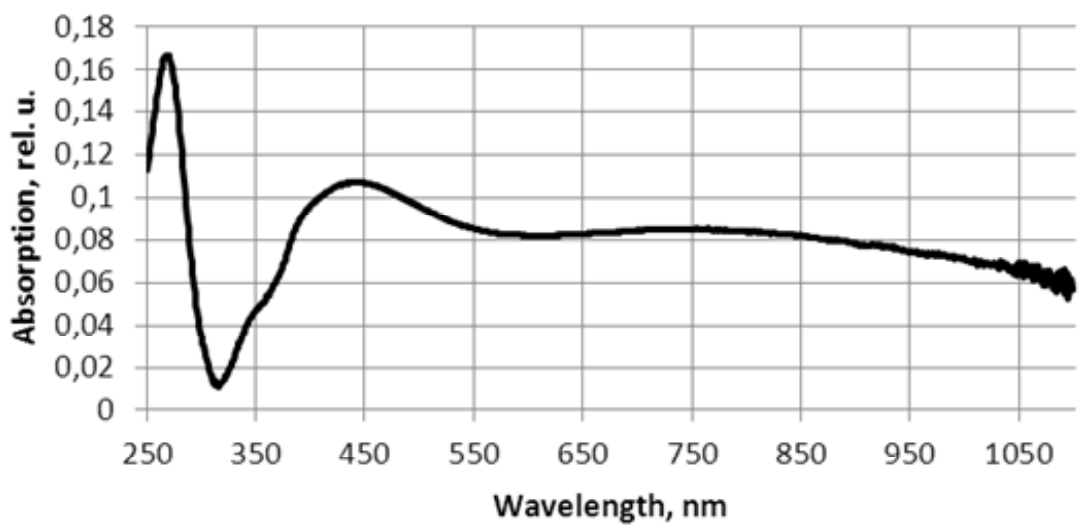

Fig. 2: Plasmon resonance spectrum of colloidal solution of silver nanoparticles prepared from silver palmitate

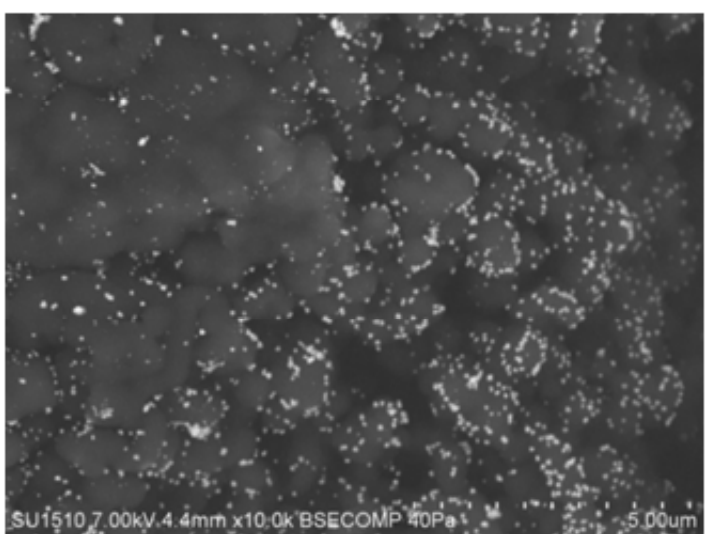

Fig. 3: SEM image of the composite obtained in ethanol

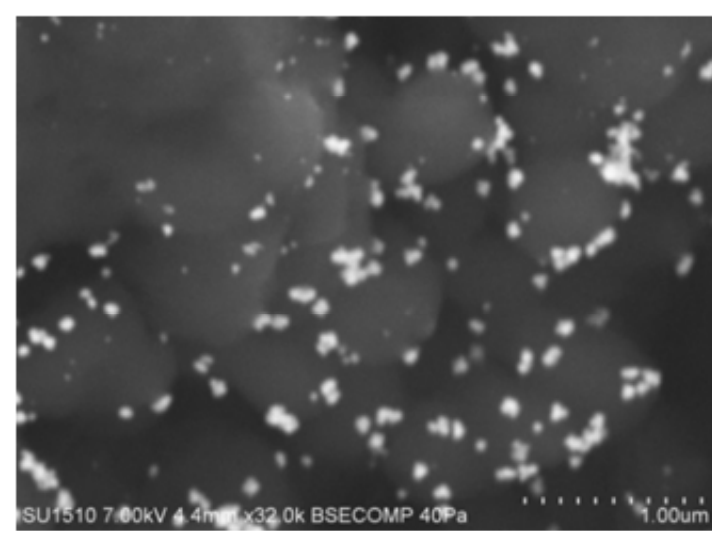

Fig. 4: SEM image of the composite obtained in methanol 
stirrer. The mixture was heated for 20 minutes at $65^{\circ} \mathrm{C}$. The solution turned yellow and aggregated very quickly.

Results for obtaining dispersions of silver nanoparticles by reduction of fatty acid salts are presented in Table 1.

The method of experiments with silver carboxylates in UHMWPE matrix

Silver laurate $0.0061 \mathrm{~g}\left(2 \cdot 10^{-4} \mathrm{M}\right)$ was dissolved in $20 \mathrm{ml}$ of ethanol for 6 hours at $50^{\circ} \mathrm{C}$. The reaction mixture was cooled to room temperature and $0.5 \mathrm{~g}$ of UHMWPE was added, then $10 \mathrm{ml}$ of ascorbic acid solution in ethylene glycol with a

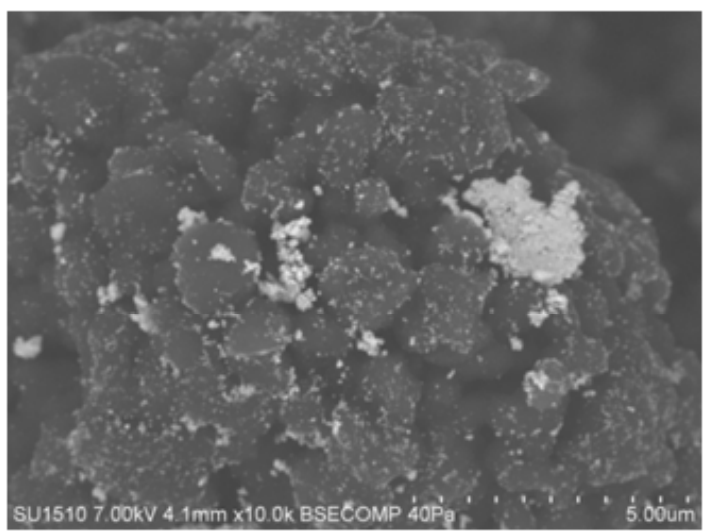

Fig. 5: SEM image of the composite obtained in ethylene glycol

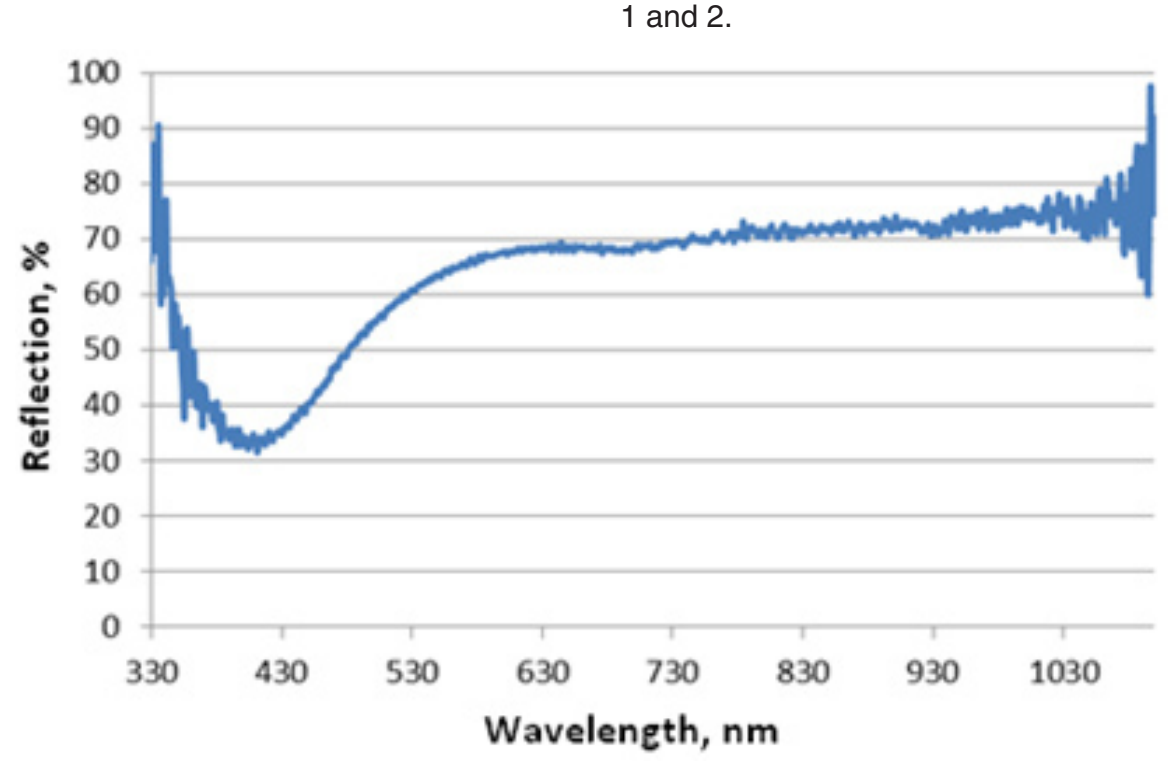

concentration of $10^{-3} \mathrm{M}$ was poured while stirring in a magnetic stirrer.

The gray-green reaction mixture was stirred for 4 hours, UHMWPE was filtered and washed with distilled water. The filtrate was colorless, UHMWPE was gray. UHMWPE was dried in an oven at $110^{\circ} \mathrm{C}$ for an hour, and it turned yellowish.

The filtrate was examined using electron spectroscopy.

\section{RESULTS AND DISCUSSIONS}

Thus as a result of studies, it was found that in the preparation of silver nanoparticles from its carboxylates by chemical reduction in non-aqueous media by using ascorbic acid and potassium citrate, in most cases we obtained unstable colloids which aggregated within several minutes. The most stable, at least for one day, were dispersions obtained when we used ascorbic acid solution in ethylene glycol with a concentration of $10^{-3} \mathrm{M}$ as the reducing agent, and ethanol with a precursor concentration of $10^{-3} \mathrm{M}$ therein as a solvent for silver carboxylate. In this case, with silver laurate the process runs at a temperature of $50^{\circ} \mathrm{C}$ and with silver palmitate at room temperature.

Plasmon resonance spectra of the most stable colloidal solutions are presented in Figures 1 and 2.

Fig. 6: Diffuse reflection spectrum of the UHMWPE modified by silver nanoparticles 
Table 1 presents the results of research on the preparation of colloid solutions of silver nanoparticles from its carboxylates.

Due to the instability of the dispersions obtained, it was carried out an experiment to obtain silver nanoparticles from silver carboxylates in the polymer matrix by reduction of ascorbic acid using ultrahigh molecular weight polyethylene (UHMWPE) as a polymer matrix at a temperature of $50^{\circ} \mathrm{C}$.

Ethylene glycol was used as a solvent for ascorbic acid, and ethanol, methanol and ethylene glycol were used as the solvent for the silver carboxylates. By scanning electron microscopy, it was revealed that when using ethanol as the solvent, spherical shape particles with diameter not exceeding $100 \mathrm{~nm}$ (Fig. 3) are evenly distributed on the surface of UHMWPE, when using methanol, the larger particles are evenly distributed in UHMWPE (Fig.4) and a large number of aggregates are obtained in ethylene glycol (Fig. 5).Diffuse reflection spectrum of obtained UHMWPE impregnated with silver nanoparticles is shown in Figure 6.

The silver content in the resulting composites is equal to 0.19 to $0.25 \%$ when using laurate and 0.025 to $0.038 \%$ when using silver palmitate according to standard penetration test on mass spectroscopy.

\section{CONCLUSION}

It is found that, when using chemical reduction of silver carboxylates in non-aqueous media, the dispersion obtained are volatile in organic compounds, aggregating within a short period. Therefore, it can be concluded, that silver nanoparticles from its carboxylates are necessary to obtain by their stabilization in the polymer matrix.

It is preferably to carry out UHMWPE impregnation using silver laurate when dissolving it in ethyl alcohol, as we obtain the composite with a narrow distribution of nanoparticles with size of evenly distributed on the surface of UHMWPE with a high silver content compared to silver palmitate used for this purpose.

\section{ACKNOWLEDGMENTS}

The applied researches are carried out with financial support of the state by the Russia Ministry of Education and Science under Grant Agreement No.14.576.21.0024 of June 27, 2014. (project 1 RFMEFI57614X0024).

\section{REFERENCES}

1. Pomogailo, A. D.; Uflyand, I. E. Metal nanoparticles in polymers. M.: Chemistry. 2000, 672

2. Bespalov, A. V.; Buiklisky V. D. Chemistry and Chemical Engineering. 2012, 55(3), 59-61

3. Panacek, À.; Kvitek, L.; Prucek, R.; Kolar, M. J. Am. Chem. Soc. 2006, 26(16), 37-43

4. Kosobudsky, I.D.; Kulbatsky D.M.; Muzalev, P.A. Chemistry and Chemical Engineering. 2011, 54(4), 97-100

5. Taylor, M. R. Washington: Woodrow Wilson International Center for Scholars, 2008, 100

6. Krutyakov, Yu. A.; Kudrinskiy, A. A.; Olenin A. Yu. Russian Chemical Reviews. 2003, 77(3),
242-269

7. Peng, K; Qian, K; Chen, W. Mater. Sci. Eng., A, 2004, 379, 378-383

8. Litmanovich, O. E. High molecular compounds. Series C. 2008, 50(7), 1370

9. Xu, J.; Han, X.; Liu, H.; Hu, Y. Colloids Surf. A, 2006, 273, 179.

10. Zana, R. Adv. Colloid Interface Sci. 2002, 97, 205.

11. Sharafutdinov, M.R. Preparation and research using in situ method for synchrotron radiation diffraction of order structures of silver nanoparticles by thermal decomposition of its carboxylate, diss.k.h.n., Novosibirsk, 2009, 105. 